\title{
Motivational factors for initiating, implementing, and maintaining physical activity behavior following a rehabilitation program for patients with type 2 diabetes: a longitudinal, qualitative, interview study
}

This article was published in the following Dove Press journal:

Patient Preference and Adherence

\author{
Karen Christina Walker \\ Laura Staun Valentiner ${ }^{1,2}$ \\ Henning Langberg' \\ 'CopenRehab, Section of Social \\ Medicine, Department of Public \\ Health, Faculty of Health, ${ }^{2}$ Center \\ for Physical Activity Research, \\ Department of Infectious Diseases, \\ Rigshospitalet, University of \\ Copenhagen, Copenhagen, Denmark
}

Correspondence: Karen Christina Walker

CopenRehab, Section of Social Medicine, Department of Public Health, Faculty of Health, Henrik Pontoppidans Vej 6, Ist floor DK-2200 Copenhagen N, Denmark Tel +4535333942 Email karw@sund.ku.dk
Aim: To explore motivational factors for initiating, implementing, and maintaining physical activity following a rehabilitation program for patients with type 2 diabetes mellitus.

Methods: Semi-structured, individual, qualitative interviews with five informants from the InterWalk trial were conducted at three separate occasions; at initiation of the rehabilitation program, at completion of the 12-week program, and 52 weeks after enrolment. Interviews were audio-recorded, transcribed, and analyzed according to Systematic Text Condensation. The framework of Self-Determination Theory was applied to guide analysis after identification of preliminary themes.

Results: Commitment and obligation were emphasized as being motivational in initiating physical activity. Toward the termination of the program, this was challenged by an expressed need for autonomy. Successful behavioral change was characterized by transfer of commitment to a new structure in everyday life, which also honored the request for autonomy. Feeling capable of participating in physical activity was facilitated through knowledge, practical experience, and progress and considered motivational, whereas lack of progress extinguished motivation. Finally, enjoyment of the activity was determining for long-term maintenance of physical activity behavior.

Conclusion: Satisfaction of innate psychological needs leads to more autonomous regulation of behavior and, through this study, we investigated determining factors for extrinsically motivated behavior and factors of importance to the internalization process.

Keywords: self-determination theory, type 2 diabetes mellitus, adherence, behavioral change, motivation

\section{Introduction}

Evidence indicates that regular physical activity reduces the risk of several noncommunicable diseases and age-related cognitive decline, and results in improvements of important health outcomes in patients with type 2 diabetes mellitus (T2DM). ${ }^{1-3}$ However, patients with, or at risk of developing, T2DM report lower levels of physical activity than adults without T2DM. ${ }^{4}$ Moreover, older patients with diabetes mellitus (DM) are less likely to meet recommended levels of physical activity as compared to peers without DM. ${ }^{5}$ The prevalence of T2DM has increased considerably during past decades, and is predicted to increase globally by 54\% from 2010 to $2030{ }^{6}$ T2DM is a chronic disease associated with comorbidities, including cardiovascular diseases, retinopathy, nephropathy, peripheral neuropathy, ulcers, and amputations. ${ }^{7}$ 
Supervised physical training as part of rehabilitation has been initiated to assist self-management of T2DM and has been shown to improve glycemic control and physical fitness in patients with T2DM. ${ }^{8-10}$

Beneficial health effects are compromised by low adherence rates to lifestyle changes, including physical activity behavior. Adherence to lifestyle changes has been reported at $50 \%$, and long-term adherence to increased physical activity in patients with T2DM has been reported to vary between $10 \%$ and $80 \% .^{11,12}$ Maintaining long-term behavioral change without supervision requires motivation from the individual toward the activity. Previous studies have investigated motivational factors and barriers to physical activity at single occasions, and established a range of demographic, psychological, and social factors including poor physical condition, lack of knowledge, social support, goal-setting, and logistic challenges. ${ }^{11,13,14}$ However, to explore processes of behavioral change from a long-term perspective, we propose a longitudinal design. A longitudinal qualitative study provides information on motivation over time to establish determining factors for long-term adherence following a rehabilitation program. Ultimately, these factors should be addressed in successfully developed rehabilitation programs aimed at patients with T2DM.

The primary objective of the present study is to address the gap in knowledge on motivational changes over time to improve adherence to physical activity from the initiation of behavioral change in a rehabilitation program, to implementation of physical activity outside the program, and, finally, to maintenance of physical activity behavior in everyday life.

\section{Methods}

\section{Study design}

We conducted individual semi-structured interviews at three separate occasions to investigate motivational factors for physical activity among participants enrolled in a rehabilitation program that targeted patients with T2DM. Informants were interviewed within the first week of enrolment, after termination of the rehabilitation program, and, finally, 1 year after enrolment to capture motivational changes over time. Semi-structured interviews are particularly well suited to identify individual experiences. ${ }^{15,16}$

\section{Study population}

Informants were recruited from the InterWalk trial - a threearm, pragmatic, randomized, controlled trial implemented in the city of Copenhagen. ${ }^{17}$ The three arms represented one control arm and two experimental arms. The control arm comprised a standard rehabilitation program with patient education and physical training offered by the municipality. Both the experimental arms offered interval walking training facilitated by an application for a smartphone or iPod called the InterWalk app instead of the standard physical training. The InterWalk app dictated the pace of the interval walking training based on an individual's walking test. ${ }^{18}$ The intervention ran for a total of 52 weeks but only the initial phase of 12 weeks included training at the health promotion center. A detailed description of the trial can be found elsewhere. ${ }^{17}$ To secure representation of the different health promotion centers - for both genders and the trial and control group, purposive sampling was applied and six newly enrolled informants were invited to participate.

\section{Data collection}

Data were collected through semi-structured interviews carried out by the first author of the present study, KCW. An interview guide was developed on the basis of reflections between the first and the second author of the study, KCW and LSV and from a review of the literature on lifestyle behavioral change in those chronically ill. The interview guide covered essential themes of initiating, implementing, and maintaining physical activity behavior (Table 1). The interview guide was adjusted between individual interviews to pursue and validate emerging topics and then further developed between the three separate occasions of interviews. Statements from informants were validated during interviews with repeated questions and with cross-interview validation. ${ }^{16}$

Principles of good ethical research practice were followed. Informants received verbal and written information about the purpose of the study and had at least 24 hours to consider their participation. Written informed consent forms were obtained at the first interview, and the informants agreed to the interviews being audio-recorded. According to Danish legislation, interview studies do not require approval from an ethics committee, but the present study was reported to The

Table I Themes from the interview guide for interviews at baseline, 12 weeks, and 52 weeks

\begin{tabular}{l} 
Themes \\
I. Initial motivation toward physical activity \\
2. Integration of physical activity in everyday life - barriers and facilitators \\
3. Intentions toward maintaining physical activity behavior \\
4. Assessment of the training program from the perspective of the \\
informant (added to the I2-week and 52 -week interviews) \\
5. The experienced long-term impact on physical activity of a \\
rehabilitation program (added to the 52 -week interview) \\
\hline
\end{tabular}


Regional Ethics Committee (VEK) of the Capital Region of Denmark (17011670). The individual interviews lasted, on average, 45 minutes (range 30-65 minutes). Interviews took place in a quiet room at the research unit or at the health promotion center.

\section{Data analysis}

All interviews were transcribed verbatim by the first author KCW. Emotional expressions such as laughter and pauses were noted in the transcript to ensure correct interpretation. The analytical process was carried out by following the stepwise directions suggested by Malterud in Systematic Text Condensation (STC). ${ }^{19}$ The first step of analysis was inductively driven; transcripts were read in full several times and possible themes were considered. Second, meaning units containing information on motivational factors for physical activity were identified and coded into groups representing different aspects of motivation inspired by the initial impression. A deductively driven approach was employed, and theoretical perspectives from the Self-determination Theory (SDT) were introduced at the second step of analysis to guide the interpretive focus. Specifically, the three innate psychological needs from the SDT were suitable and in alignment with preliminary findings from the initial read-through and, therefore, guided the analysis. The headings of the main findings were not the innate psychological needs but empirically founded. Third, meaning units within each code were divided into subgroups. Fourth, an analytical text was created from the codes and re-contextualized - that is, considered in connection with the entire material to ensure validity. The codes were constantly reflected upon and challenged, and documented in a decision trail (not shown).

The SDT has previously been used to investigate motivational factors for physical activity among several population groups. $^{20,21}$ The SDT distinguishes between several types of extrinsic motivation varying in degree of self-determination placed along a continuum with amotivation - representing a lack of intention to act - and intrinsic motivation at the opposite end. ${ }^{22}$ Intrinsically regulated behaviors are undertaken due to the inherent satisfaction of the activity and are completely self-determined. In contrast, extrinsically regulated behaviors are engaged in to obtain a separable outcome and vary in degree of self-determination. An essential notion of the SDT is the process of internalization of non-self-determined behaviors to become more selfdetermined and integrated as part of the individual, thereby securing greater persistence toward the behavior. ${ }^{23}$ Further, SDT addresses the influence of social-contextual factors on this process. ${ }^{23}$ Through empirical research, three innate needs - competence, relatedness, and autonomy - have been identified to influence the process of internalization and the degree of self-determination in motivation toward a given behavior, and, when satisfied, these facilitate the integration of an extrinsically motivated behavior. ${ }^{22}$ The need for competence refers to the need to accomplish a task successfully by achieving the desired outcome. The need for relatedness covers the need for mutual and respectful unity with others. Finally, the need for autonomy is the need to experience a sense of choice and own free will as well as a personal rationale to take part in a certain behavior. ${ }^{24}$ Particularly, the concept of the innate psychological needs was used to sharpen the analysis of the empirical data. The three rounds of interviews were initially analyzed separately, followed by a comparison analysis to establish development in motivational factors over time.

The codes from the three separate rounds of interviews were developed by KCW and continuously discussed with a second investigator, LSV. Any disagreements were resolved by discussion with a senior researcher, HL. Data were managed using Nvivo version 11.2.1.616 (32-bit).

\section{Results}

Characteristics of the included informants are stated in Table 2. The same informants participated in all three rounds of interviews, but one moved away prior to the first interview and two were lost to follow-up 52 weeks after the baseline. One declined to participate (informant 4), and one could not be reached (informant 2). The average age of the informants was 58 years ( $41-70$ years). The majority were men $(80 \%)$, and all were enrolled in the InterWalk trial. The informants represented three different health promotion centers and both the intervention and the control group.

Table 2 Characteristics of informants

\begin{tabular}{llllll}
\hline Characteristics & Informant I & Informant 2 & Informant 3 & Informant 4 & Informant 5 \\
\hline Gender & Male & Male & Male & Male & Female \\
Age (years) & 70 & 57 & 41 & 66 & 57 \\
Center & 1 & 2 & 2 & 3 & 2 \\
Group & Intervention & Intervention & Control & Intervention & Intervention \\
\hline
\end{tabular}


Two overarching themes were identified as motivational changes for physical activity over time: 1 . Balancing the need for commitment and a sense of choice and 2. Feeling competent and experiencing progress. The overarching themes each encompassed three subthemes from the analysis of the three separate rounds of interviews at baseline, 12 weeks, and 52 weeks. Further, a minor theme based on subthemes from the baseline interview and 52-week interview was identified. 3. Setup, surroundings, and the actual activity. The minor theme was not present at the 12-week interview and, hence, the definition as a minor theme. Figure 1 gives an overview of the overarching themes and subthemes as well as the minor theme and subthemes. Findings are presented and elaborated on below with key quotations.

\section{Balancing the need for commitment and a sense of choice \\ Commitment fosters physical activity - baseline interview}

Initially, feeling committed toward the program and stakeholders within the program was a common motivator expressed by informants. Some informants uttered a request for stability and continuity, as they had been unable to set up structures by themselves to support behavioral change in their physical activity habits.

I sit at home and say to myself "come on - get out and go for a walk, come on - get out" but nothing happens. I need a push by someone. (informant 4 )
Informants explained how the presence of instructors as well as the structure and the continuity of the program made it impossible to procrastinate being physically active. Moreover, informants felt obligated to show up and attend the program once they had committed to it.

\section{Physical activity challenged by other commitments - I2-week interview \\ Commitment and obligation toward someone was still emphasized by some informants as an important factor in maintaining their behavioral change following the termina- tion of the program.}

You can have a lot of intentions about continuing on your own but that can disappear all of a sudden, but then it (structure) will still keep you going. (informant 4)

The request for a continued commitment was, however, challenged by an expressed desire to regain a sense of choice and autonomy. The time schedule of the program conflicted with other priorities in the everyday lives of informants including working hours, and had forced some informants to change routines and abandon other commitments.

It has been stressful because I also attend mindfulness on Mondays ... After Christmas I will go back to my normal training days and make a new training schedule. (informant 5)

As a consequence, one informant had stopped attending the program altogether, whereas several others uttered that

\section{Overarching themes}

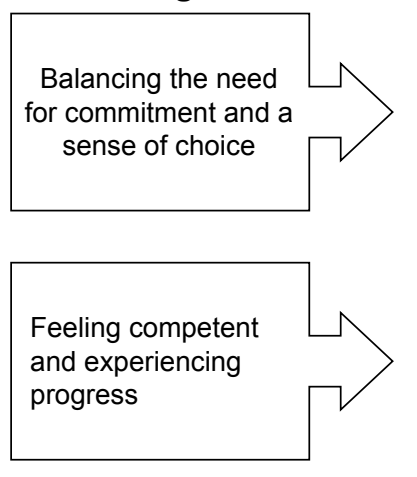

Minor theme

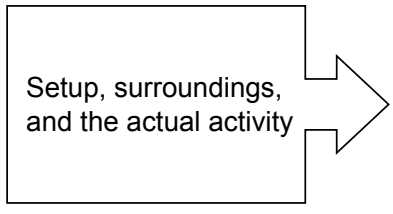

Commitment fosters phy

\section{Subthemes}

Physical activity challenged by other commitments
Transfer of commitment to a new structure
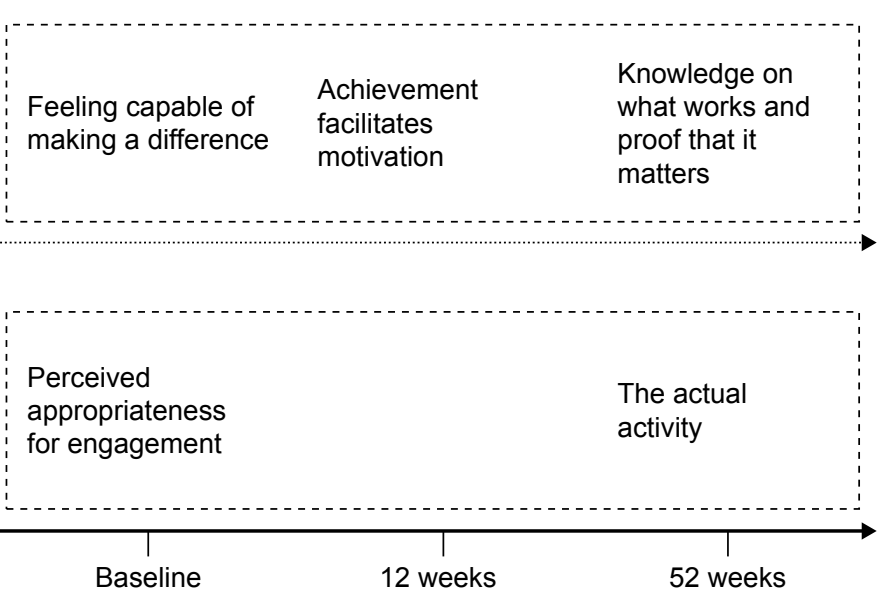

Figure I Main findings presented with subthemes from interviews at baseline, 12 weeks, and 52 weeks. 
they were relieved that the program was over, so they could regain control of their own routines.

\section{Transfer of commitment to a new structure - 52-week interview}

Some informants had successfully transferred the commitment they found motivating to a new structure that facilitated being physically active. The new structure was, in one case, a group of people meeting daily on a voluntary basis to do interval walking together and, in another case, an agreement with one other person to meet regularly and undertake interval walking combined with other activities. The new structures accommodated both the desire for a sense of choice as well as satisfied the request for commitment. One informant was no longer active, as he had not engaged in a new commitment.

Nobody is expecting me to do it (physical activity) so quite quickly I'll say "tomorrow you'll go to the fitness center" and then tomorrow it's postponed till the day after and suddenly a month has gone by. (informant 3 )

The need for relatedness was brought up more frequently at the first interview and, to a lesser but still important degree, at 12 weeks and, finally, again at the final interview. The attenuation of the importance of commitment was accompanied by a rising need for autonomy and a sense of choice. The conflict between these two needs was resolved at the final interview for informants who had managed to satisfy their need for relatedness in a new structure.

\section{Feeling competent and experiencing progress}

\section{Feeling capable of making a difference - baseline interview}

Several informants said that they wanted to be able to fight the adverse health consequences of diabetes they feared would affect them in the future.

... I felt that I had to do something. Diabetes is really awful and the thought of the consequences really scared me. (informant 2)

The fear of comorbidities and the opportunity offered by the program to make a difference was very motivating for the informants. All informants felt capable of engaging in physical activity routines presented in the program and felt motivated by the thought of progress. Being competent to achieve progress in terms of fitness level, weight loss, or well-being was a main motivational factor for engaging in physical activity.

\section{Achievement facilitates motivation - I2-week interview}

When informants progressed, it added to their desire to continue and achieve more in terms of benefiting their condition.

I would say a quick weight loss of 5-10 kilos would do wonders. It would really be motivating. You want to get into a loop where you eat right because you are exercising and you are exercising because you are losing weight. (informant 3)

However, a lack of progress and unattained goals were devastating for motivation toward continuing to be physically active. One informant felt that his goal of weight loss had not been satisfyingly met and, therefore, felt discouraged.

\section{Knowledge on what works and proof that it matters - 52-week interview}

Gaining knowledge and practical experience was motivating for some of the participants - particularly for informants without past experience of structured physical activity.

It is very much the awareness of your own capability of making a difference ... You are in charge of what you can do and you have proof that you really can do something. (informant 1)

However, merely knowing what to do was not enough to maintain physical activity behavior. At the termination of the program and 1 year after baseline, several informants explained that knowing what to do as well as experiencing progress and reaching goals were very important for maintaining physical activity behavior. One participant did not experience progress and had stopped exercising.

Feeling capable was a constant motivational factor across all three rounds of interviews. Initially, the need for competency was satisfied by knowing what to do and being provided with the tools to do it. Later, knowledge would have to be complemented by progress and measurable changes in fitness level or weight loss to satisfy the need for competency.

\section{Setup, surroundings, and the actual activity}

Setup, surroundings, and the actual activity was identified as a minor theme in motivational change from baseline interviews to 52-week interviews. The theme encompassed the meaning of the setup and the activity on motivation for physical activity. The theme was not present at 12-week interviews. 


\section{Perceived appropriateness for engagement - baseline interview}

The actual activity and the setup of the program were emphasized by informants as appropriate, which motivated them to join. The walking activity was appealing to nearly all of the informants from the intervention group because the activity was familiar to them and in alignment with what they could see themselves doing.

I could go down to the basement and use the exercise bike, but then you look directly into a wall. I would much rather go outside and see something while I exercise. (informant 4)

Furthermore, the setup of the program was perceived as motivational by several informants. This was largely due to the trusting environment created by health professionals. Particularly, one informant mentioned that he knew of other training offers but entering a regular fitness center was perceived as uncomfortable.

In addition to the expressed perception of the activity and setup, informants described an experience of expectation from society to engage in the rehabilitation program. One informant described the rehabilitation program as a package that was offered to him by society, and another emphasized the financial contribution by the municipality to the funding of the program.

\section{The actual activity - 52-week interview}

At 1 year after enrolment, the continued engagement in physical activity depended on the enjoyment of the actual activity. Informants who had been interval walking and attended the final interview described a genuine enjoyment in doing the activity and appreciated physical activity as part of their everyday life through interval walking.

It is important that you are motivated for it (the type of physical activity). Others might prefer being inside and work out in a center. (informant 1)

The informant from the control group expressed discomfort with fitness centers and, as a result, only rarely entered a fitness center.

The appropriateness of the context and activity was highlighted at the beginning of the rehabilitation program, where enjoyment of the actual activity was emphasized at the 52-week interview. Initially, motivational factors for physical activity were encompassed in the setting and setup of the activity, whereas continuation of the activity depended on the actual type of activity.

\section{Discussion and conclusion Discussion}

The present study contributes knowledge on motivational factors for physical activity from a longitudinal study design with multiple interviews. The transition from being in a rehabilitation program to implementing new behavior in everyday life requires a new structure that satisfies all three psychological needs to promote internalization and, thereby, long-term behavioral change. The two overarching themes represent the changes in motivation from initiating to enacting and maintaining physical activity in the long term. A successful behavioral change was characterized by transfer of commitment to a new structure of physical activity, which not only should honor the need for relatedness and competence but also the request for autonomy. Further, knowledge and practical experience with physical activity and goal achievement were considered motivating whereas a lack of progress extinguished motivation.

The need for relatedness was satisfied by commitment and structure, which previously have been found to facilitate engagement in physical activity. Kerkelä et al found that the structuring of a program fostered commitment but, over time, became a restraint and resulted in agitation toward the program, similarly as in findings from the present study. ${ }^{14}$ Koestner and Losier suggest that a conflict between the satisfaction of the need for relatedness and autonomy will lead to introjected regulated behaviors based on the feeling of guilt. ${ }^{25}$ Introjected regulated behaviors can lead to anxiety and discontent, with the result that the behavior will not be internalized. ${ }^{26}$ This implies that rehabilitation programs must provide satisfaction of the need for autonomy and relatedness for physical activity behavior to be regulated by identification and, thereby, be more internalized..$^{25}$

The satisfaction of the need for competence is an essential part of internalization; Ryan and Deci also state that people are more prone to engage in activities they master and value in terms of the outcome. ${ }^{23}$ The need for competence and relatedness facilitate partial internalization whereas satisfaction of the need for autonomy is crucial for further internalization. ${ }^{24}$ Several studies have shown a positive effect on adherence to physical activity by promoting autonomous motivation. ${ }^{27,28}$ $\mathrm{Ng}$ et al found, in a meta-synthesis, that autonomy-supportive environments facilitate satisfaction of innate needs. ${ }^{26}$ These environments are characterized by respecting and involving the perspective of the individual and not by imposing values and placing external pressure on the individual. ${ }^{26}$ Standardized interventions should be adjustable in order to fit individual needs and preferences. The offered activity may 
be one opportunity to accommodate the perspective of the individual. Informants from the present study experienced different incentives to promote physical activity, that is, interval walking or training in a fitness center. The present study found that enjoyment of the activity was determinative for maintaining behavioral change in the long term. Findings from Forbes et al regarding demographic differences in physical activity preferences among patients with T2DM resonates with this and highlights the importance of tailoring the offered interventions to the individual. ${ }^{29}$ Interval walking was perceived by the majority of the informants from the intervention group as enjoyable, whereas the setting of training in fitness centers was not associated with joy and prevented the informant in the control group from maintaining the activity on a regular basis.

Another view on behavioral change is the creation of habits. Habits are characterized by the automaticity of the behavior and are cued in a specific context. ${ }^{30}$ Orbell and Verplanken highlight the potential of habits on behavioral change if underlying mechanisms are clear and further emphasize that breaking old habits may provide an opportunity for interventions. ${ }^{30}$ The specific context of the individual should be taken into account, as the creation of healthy habits or prevention of unhealthy habits in combination with an autonomy-supportive environment could facilitate long-term behavioral change.

\section{Method discussion}

Some methodological considerations are needed. Individual semi-structured qualitative interviews are a preferred method for exploring individual experiences and perceptions about a given issue, and longitudinal design fosters a greater understanding of changing experiences or attitudes over time. ${ }^{15,31,32}$ The internal validity of the present study was strengthened during interviews with clarifying questions throughout the interviews to minimize misinterpretations. Further, the trustworthiness of the findings was increased by following the stepwise analysis of the STC. Validity was sought after through transparency of the analysis, and re-contextualization of the findings ensured a loyal portrayal of the empirical data. ${ }^{33}$ A limitation of the study was the low number of informants. At the time of recruitment, only a few participants were enrolled in the InterWalk trial and, thereby, eligible for inclusion, and most were randomly assigned to the intervention group and most were men. Only three participants took part in the final interview. A larger representation of females, younger participants, and participants from the control group may have led to more information on motivational factors for physical activity, and a larger sample could have nuanced the findings and made transferability greater. Apart from the mentioned limitations on the study population, the population consisted of both genders, represented different health promotion centers, and both the experimental and control intervention. Further, the coding process was carried out by one author, $\mathrm{KCW}$, which could have compromised the reflexivity of preconception. ${ }^{33}$ However, the findings were discussed with a second author, LSV, and constantly reflected upon. Preconceptions were further challenged by introducing statements between interviews, but abandoned if informants did not voluntarily elaborate on the issue. The theoretical framework, which was familiar to the author prior to the interviews, was also continuously reflected upon, and an initial inductive approach was employed at the first step of analysis to allow for empirical findings to emerge.

\section{Conclusion and practice implications}

Patients commonly take part in medical regimens for which they are not intrinsically, but extrinsically, motivated. ${ }^{34}$ Satisfaction of the innate psychological needs will, however, lead to more autonomous regulation of behavior and, through this study, we have investigated determining factors at play in extrinsically motivated behavior as well as the transfer of motivation toward internalization. Findings from the present study can be used in the design of interventions aimed at behavioral change.

Personal identifiers have been removed or disguised so that persons described herein are not identifiable.

\section{Acknowledgments}

This study was funded by a research grant from Foundation for Intersectorial Research Projects. The sponsors of this study did not play a role in the design, analysis, or interpretation of data.

\section{Author contributions}

LSV presented the initial idea of the study. LSV and KCW collaborated on the final design, the recruitment strategy, and the interview guide. KCW conducted and transcribed the interviews and established the initial interpretation of the data. LSV supported the analysis and HL and LSV provided feedback on findings and added to the final analysis. All authors contributed toward data analysis, drafting and revising the paper and agree to be accountable for all aspects of the work.

\section{Disclosure}

KCW and LSV also received funding from Tryg Foundation and LSV from Danish Association of Physiotherapists. LSV and 
HL further received funding from the City of Copenhagen. The authors report no other conflicts of interest in this work.

\section{References}

1. Powell KE, Paluch AE, Blair SN. Physical activity for health: What kind? How much? How intense? On top of what? Annu Rev Public Health. 2011;32:349-365.

2. Chieffi S, Messina G, Villano I, et al. Neuroprotective effects of physical activity: evidence from human and animal studies. Front Neurol. 2017;8:188.

3. Sigal RJ, Kenny GP, Boulé NG, et al. Effects of aerobic training, resistance training, or both on glycemic control in type 2 diabetes: a randomized trial. Ann Intern Med. 2007;147(6):357-369.

4. Morrato EH, Hill JO, Wyatt HR, Ghushchyan V, Sullivan PW. Physical activity in U.S. adults with diabetes and at risk for developing diabetes, 2003. Diabetes Care. 2007;30(2):203-209.

5. Zhao G, Ford ES, Li C, Balluz LS. Physical activity in U.S. older adults with diabetes mellitus: prevalence and correlates of meeting physical activity recommendations. J Am Geriatr Soc. 2011;59(1):132-137.

6. Shaw JE, Sicree RA, Zimmet PZ. Global estimates of the prevalence of diabetes for 2010 and 2030. Diabetes Res Clin Pract. 2010; 87(1):4-14.

7. American Diabetes Association. Diagnosis and classification of diabetes mellitus. Diabetes Care. 2010;33(Suppl 1):S62-S69.

8. Backx K, McCann A, Wasley D, Dunseath G, Luzio S, Owens D. The effect of a supported exercise programme in patients with newly diagnosed Type 2 diabetes: a pilot study. J Sports Sci. 2011;29(6):579-586.

9. Hordern MD, Cooney LM, Beller EM, Prins JB, Marwick TH, Coombes JS. Determinants of changes in blood glucose response to short-term exercise training in patients with Type 2 diabetes. Clin Sci (Lond). 2008;115(9):273-281.

10. Umpierre D, Ribeiro PA, Kramer CK, et al. Physical activity advice only or structured exercise training and association with $\mathrm{HbA1c}$ levels in type 2 diabetes: a systematic review and meta-analysis. JAMA. 2011; 305(17):1790-1799.

11. Delamater AM. Improving patient adherence. Clin Diabetes. 2006; 24(2):71-77.

12. García-Pérez LE, Alvarez M, Dilla T, Gil-Guillén V, Orozco-Beltrán D. Adherence to therapies in patients with type 2 diabetes. Diabetes Ther. 2013;4(2):175-194.

13. Lidegaard LP, Schwennesen N, Willaing I, Faerch K. Barriers to and motivators for physical activity among people with Type 2 diabetes: patients' perspectives. Diabet Med. 2016;33(12):1677-1685.

14. Kerkelä ES, Jonsson L, Lindwall M, Strand J. Individual experiences following a 6-month exercise intervention: a qualitative study. Int $J$ Qual Stud Health Well-being. 2015;10:26376.

15. Kvale S. InterView - En introduktion til det kvalitative forskningsinterview [Interview: An introduction to the qualitative research interview]. Vol 1. København: Hans Reitzels Forlag; 1997. Danish.

16. Crabtree BF, Miller WL. Depth interviewing. In: Crabtree BF, Miller WL, editors. Doing Qualitative Research. 2nd ed. Thousand Oaks, CA: SAGE Publications; 1999.
17. Valentiner LS, Ried-Larsen M, Karstoft K, et al. Long-term effect of smartphone-delivered Interval Walking Training on physical activity in patients with type 2 diabetes: protocol for a parallel group singleblinded randomised controlled trial. BMJ Open. 2017;7(4):e014036.

18. Ried-Larsen M, Thomsen RW, Berencsi K, et al. Implementation of interval walking training in patients with type 2 diabetes in Denmark: rationale, design, and baseline characteristics. Clin Epidemiol. 2016;8:201-209.

19. Malterud K. Systematic text condensation: a strategy for qualitative analysis. Scand J Public Health. 2012;40(8):795-805.

20. Thorup CB, Grønkjær M, Spindler H, et al. Pedometer use and selfdetermined motivation for walking in a cardiac telerehabilitation program: a qualitative study. BMC Sports Sci Med Rehabil. 2016;8:24.

21. Power TG, Ullrich-French SC, Steele MM, Daratha KB, Bindler RC. Obesity, cardiovascular fitness, and physically active adolescents' motivations for activity: a self-determination theory approach. Psychol Sport Exerc. 2011;12(6):593-598.

22. Deci E, Ryan R. Self-determination theory: a macrotheory of human motivation, development, and health. Can Psychol. 2008;49(3):182-185.

23. Ryan RM, Deci EL. Self-determination theory and the facilitation of intrinsic motivation, social development, and well-being. Am Psychol. 2000;55(1):68-78.

24. Ryan RM, Deci EL. Intrinsic and extrinsic motivations: classic definitions and new directions. Contemp Educ Psychol. 2000;25(1):54-67.

25. Koestner R, Losier GF. Distinguishing three ways of being internally motivated: a closer look as introjection, identification, and intrinsic motivation. In: Deci EL, Ryan RM, editors. Handbook of Self-Determination Research. Rochester, NY: University of Rochester Press; 2002.

26. Ng JY, Ntoumanis N, Thogersen-Ntoumani C, et al. Self-determination theory applied to health contexts: a meta-analysis. Perspect Psychol Sci. 2012;7(4):325-340.

27. Thøgersen-Ntoumani C, Ntoumanis N. The role of self-determined motivation in the understanding of exercise-related behaviours, cognitions and physical self-evaluations. J Sports Sci. 2006;24(4):393-404.

28. Teixeira PJ, Carraça EV, Markland D, Silva MN, Ryan RM. Exercise, physical activity, and self-determination theory: a systematic review. Int J Behav Nutr Phys Act. 2012;9:78.

29. Forbes CC, Plotnikoff RC, Courneya KS, Boule NG. Physical activity preferences and type 2 diabetes: exploring demographic, cognitive, and behavioral differences. Diabetes Educ. 2010;36(5):801-815.

30. Orbell S, Verplanken B. The automatic component of habit in health behavior: habit as cue-contingent automaticity. Health Psychol. 2010; 29(4):374-383.

31. DiCicco-Bloom B, Crabtree BF. The qualitative research interview. Med Educ. 2006;40(4):314-321.

32. Murray SA, Kendall M, Carduff E, et al. Use of serial qualitative interviews to understand patients' evolving experiences and needs. $B M J$. 2009;339:b3702.

33. Malterud K. Qualitative research: standards, challenges, and guidelines. Lancet. 2001;358(9280):483-488.

34. Markland D, Tobin VJ. Need support and behavioural regulations for exercise among exercise referral scheme clients: the mediating role of psychological need satisfaction. Psychol Sport Exerc. 2010; 11(2):91-99.
Patient Preference and Adherence

\section{Publish your work in this journal}

Patient Preference and Adherence is an international, peer-reviewed, open access journal that focuses on the growing importance of patient preference and adherence throughout the therapeutic continuum. Patient satisfaction, acceptability, quality of life, compliance, persistence and their role in developing new therapeutic modalities and compounds to optimize

\section{Dovepress}

clinical outcomes for existing disease states are major areas of interest for the journal. This journal has been accepted for indexing on PubMed Central. The manuscript management system is completely online and includes a very quick and fair peer-review system, which is all easy to use. Visit http://www. dovepress.com/testimonials.php to read real quotes from published authors. 